Journal of Thermal Engineering, Vol. 5, No. 6, Special Issue 10, pp. 240-251, December, 2019

Yildiz Technical University Press, Istanbul, Turkey

\title{
SECOND LAW ANALYSIS OF MIXED CONVECTION OF MAGNETOHYDRODYNAMIC FLOW IN AN INCLINED SQUARE LID-DRIVEN ENCLOSURE
}

\author{
E. B. Öğüt $1{ }^{*}$
}

\begin{abstract}
Second law of thermodynamics analysis is formulated for the case of laminar mixed convection in an inclined square lid-driven enclosure in the presence of magnetic field. Vertical sides of the enclosure moves upward when inclination angle is zero. Governing equations of flow and temperature in the form of stream function-vorticity formulation were solved numerically using the differential quadrature method. Governing parameters are: Richardson number (from 0.01 to 100), Prandtl number (from 0.1 to 1.0), inclination angle of enclosure (from $0^{\circ}$ to $180^{\circ}$ ), Hartmann number (from 0 to 100) and magnetic field direction $\left(0^{\circ}\right)$. It is found that the inclination angle of enclosure is effective parameter on entropy generation especially for higher Richardson number ( $\mathrm{Ri}>1$ ) due to domination of natural convection. However, Hartmann number is effective on both heat transfer and entropy generation for all values of Richardson and Prandtl numbers and it decreases the convective fluid flow and entropy generation.
\end{abstract}

Keywords: Lid-driven Enclosure, Mixed Convection, Entropy Generation, Magnetic Field

\section{INTRODUCTION}

Flow fields and temperature distributions in lid-driven cavities are important for both thermal sciences and fluid mechanics due to their importance in areas such as cooling of electronic devices, geothermal applications, furnaces, air-solar collectors etc. Shankar and Despande [1] showed an example for the lid-driven configuration. They indicated that in the short-dwell coater used to produce high-grade paper and photographic film, the structure of the field in the liquid pond can greatly influence the quality of the coating on the roll and the cavity is a rectangular parallelepiped in which the lid generates the motion. This phenomenon contains pure fluid motion. Ghia et al. [2] performed a study to show the flow fields inside the lid-driven enclosure as a benchmark study. When a temperature gradient is imposed such that the shear driven and buoyancy effects are of comparable magnitude then the resulting flow falls under mixed convection regime as indicated by Sharif [3]. In this case, the analysis becomes more complex. Investigation of opposing or aiding mechanism of the mixed convection is performed by Torrance et al. [4], Iwatsu et al. [5] and Mohammad and Viskanta [6]. Control of heat transfer is very important issue in both industrial heat transfer and other applications from the energy saving point of view. One way of this control parameter is application of magnetic field at different directions. It is important especially in crystal growth processes. In earlier studies, effects of magnetic field on natural convection heat transfer in enclosures with different configurations have been studied by Buyuk [7] and Ece and Buyuk [8]. Magnetohydrodynamic mixed convection also important for channel flows as studied by Chamkha [9]. However, Chamkha [10] made a numerical analysis to obtain flow and temperature field of hydromagnetic combined convection flow in a lid-driven enclosure with left side moves up/down with internal heat generation or absorption. They solved the governing equations based on finite-volume approach along with the ADI scheme. They found that flow behavior and the heat transfer characteristics inside the cavity are strongly affected by the presence of the magnetic field. Significant reductions in the mean Nusselt number were produced for both aiding and opposing flow situations as the strength of the applied magnetic field was increased.

The best way of analysis of the thermofluid problems is second-law analysis of thermodynamics and its design-related concept of entropy generation and minimization. Entropy generation minimization is the method of modeling and optimization of real devices that owe their thermodynamic imperfection to heat transfer, mass transfer, and fluid flow irreversibilities [11]. Thus, the method combines the three scientific areas as thermodynamics, heat

This paper was recommended for publication in revised form by Regional Editor Hakan Demir

${ }^{1}$ Department of Vocational School, Kocaeli University, Kocaeli, TURKEY

${ }^{\star}$ E-mail address: elif.ogut@kocaeli.edu.tr

Orcid id:https: 0000-0001-7037-9018

Manuscript Received 7 February 2018, Accepted 5 April 2018 
transfer and fluid mechanics. The existence literature showed that there are many studies on entropy generation due to natural [12-14] or mixed convection [15-17] in enclosures and ducts. Mansour et al. [15] made an analytical study to investigate the dissipation and entropy generation in fully developed forced and mixed laminar convection in a vertical tube. They used power series expansion of the axial velocity to solve the coupled partial differential equations. Tasnim and Mahmud [16] examined the entropy generation for mixed convection flow in a vertical annular space. Mahmud and Fraser [17] investigated the mixed convection including Radiation and magnetic forces analytically. They analysed the entropy generation. They observed that entropy generation number is characterized by the concave shaped profile and is symmetric about the channel centerline for symmetrical temperature boundary conditions.

To the best knowledge of the present author no attention has been paid to analyze of entropy generation due to mixed convection in an inclined lid-driven enclosure under magnetic field. Mainly, the study is an extended study by adding the second law analysis to the study performed by Buyuk [7]. The effects of key governing parameters effective on entropy generation, heat transfer and flow field are investigated. These parameters are Richardson number, inclination angle of the enclosure, Prandtl number.

\section{PHYSICAL MODEL}

Considered physical model is shown in Figure 1 with coordinate system and boundary conditions, schematically. Inclination angle of the enclosure with respect to coordinate system is also shown in Figure. It is a square inclined lid-driven enclosure. Moving sides of the enclosure are isothermal and they have different temperature. They have constant speed as U. In the figure, $\mathrm{T}_{1}>\mathrm{T}_{0}$. Other two sides are kept adiabatic. Magnetic field of strength $\mathrm{B}$ is applied at an angle $\varphi$ according to coordinate system.

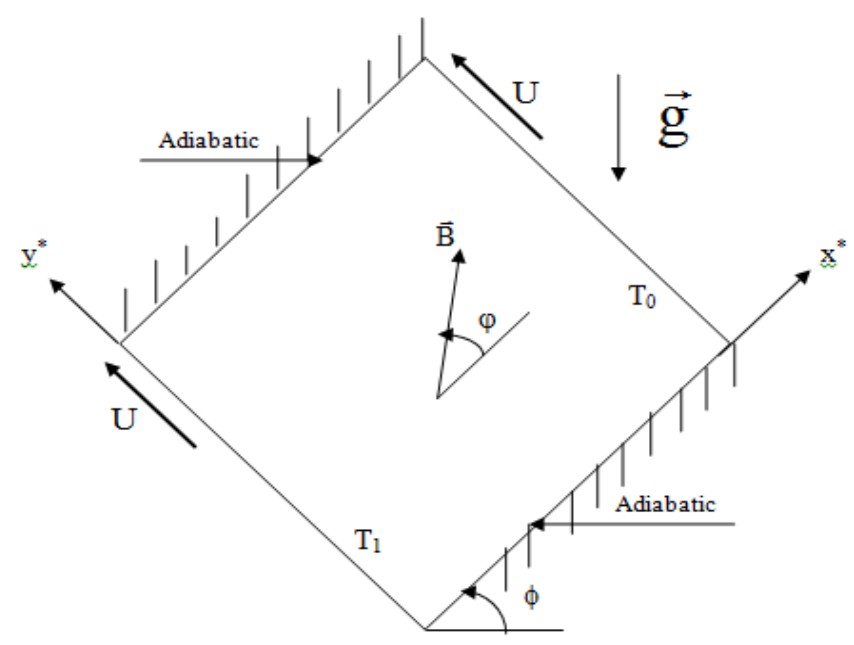

Figure 1. Schematic diagram of the physical system

\section{COMPUTATIONAL DETAILS}

Steady, laminar, mixed convection flow under the presence of a magnetic field in an inclined square enclosure with isothermally heated and moving side walls, and stationary and adiabatic horizontal walls was considered. Dimensional coordinates with the $\mathrm{x}^{*}$-axis measuring along the bottom wall and $\mathrm{y}^{*}$-axis being normal to it along the left wall were used. The geometry and the coordinate system are schematically shown in Fiure 1. The angle of inclination of the enclosure is denoted by $\phi$. Magnetic field of strength B is applied at an angle $\varphi$. The top and the bottom walls are insulated and the fluid is isothermally heated and cooled by the left and the right side walls at uniform temperatures of $T_{1}$ and $T_{0}$, respectively. The vertical walls are also allowed to move with equal and constant velocity in the same or opposite directions.

Dimensionless variables used in the analysis are: 
Journal of Thermal Engineering, Research Article, Vol. 5, No. 6, Special Issue 10, pp. 240-251,

$$
\begin{gathered}
x=\frac{x^{*}}{L}, \quad y=\frac{y^{*}}{L} \\
\mathrm{u}=\frac{\mathrm{u}^{*}}{\mathrm{U}}, \quad \mathrm{v}=\frac{\mathrm{v}^{*}}{\mathrm{U}}, \quad \mathrm{p}=\frac{\left[\mathrm{p}^{*}+\rho_{0} \mathrm{~g}\left(\mathrm{x}^{*} \sin \phi+\mathrm{y}^{*} \cos \phi\right)\right]}{\rho_{0} \mathrm{U}^{2}}, \quad \theta=\frac{\mathrm{T}-\mathrm{T}_{0}}{\mathrm{~T}_{1}-\mathrm{T}_{0}} .
\end{gathered}
$$

Here $\mathrm{g}$ is the gravitational acceleration, $\mathrm{L}$ is the dimensional length of the square enclosure, $\mathrm{U}$ is the velocity of the side walls of the enclosure, $\mathrm{u}^{*}$ and $\mathrm{v}^{*}$ are the dimensional velocity components in the $\mathrm{x}^{*}$ and $\mathrm{y}^{*}$ directions respectively, $\mathrm{p}^{*}$ is the dimensional pressure and $\rho_{0}$ is the density of the fluid at temperature $T_{0}$.

A dimensionless stream function and vorticity were defined as follows,

$$
\begin{gathered}
u=\frac{\partial \psi}{\partial y}, \quad v=-\frac{\partial \psi}{\partial x} \\
\omega=\frac{\partial v}{\partial x}-\frac{\partial u}{\partial y}
\end{gathered}
$$

The governing equations under Boussinesq approximation in terms of the dimensionless variables may then be written as:

$$
\begin{aligned}
& \omega=-\nabla^{2} \psi \\
& u \frac{\partial \omega}{\partial x}+v \frac{\partial \omega}{\partial y}=\frac{1}{\operatorname{Re}}\left(\frac{\partial^{2} \omega}{\partial x^{2}}+\frac{\partial^{2} \omega}{\partial y^{2}}\right)+\frac{G r}{\operatorname{Re}^{2}}\left(\cos \phi \frac{\partial \theta}{\partial x}-\sin \phi \frac{\partial \theta}{\partial y}\right) \\
& +\frac{\mathrm{Ha}^{2}}{\operatorname{Re}}\left[\cos \varphi\left(\sin \varphi \frac{\partial \mathrm{u}}{\partial \mathrm{x}}-\cos \varphi \frac{\partial \mathrm{v}}{\partial \mathrm{x}}\right)+\sin \varphi\left(\sin \varphi \frac{\partial \mathrm{u}}{\partial \mathrm{y}}-\cos \varphi \frac{\partial \mathrm{v}}{\partial \mathrm{y}}\right)\right] \\
& \mathrm{u} \frac{\partial \theta}{\partial \mathrm{x}}+\mathrm{v} \frac{\partial \theta}{\partial \mathrm{y}}=\frac{1}{\operatorname{RePr}}\left(\frac{\partial^{2} \theta}{\partial \mathrm{x}^{2}}+\frac{\partial^{2} \theta}{\partial \mathrm{y}^{2}}\right)
\end{aligned}
$$

Here the Reynolds, Prandtl, Grashof and Hartman numbers are defined as follows

$$
\operatorname{Re}=\frac{\mathrm{UL} \rho_{0}}{\mu}, \operatorname{Pr}=\frac{\mu}{\rho_{0} \alpha}, \operatorname{Gr}=\frac{\rho_{0}^{2} g \mathrm{LL}^{3}\left(\mathrm{~T}_{1}-\mathrm{T}_{0}\right)}{\mu^{2}}, \mathrm{Ha}=\mathrm{LB} \sqrt{\frac{\sigma}{\mu}}
$$

where $\mu$ is the viscosity, $\beta$ is the coefficient of thermal expansion, $\alpha$ is the thermal diffusivity and $\sigma$ is the electrical conductivity of the fluid respectively. Boundary conditions are

$$
\begin{gathered}
\mathrm{u}(\mathrm{x}, 0)=0, \mathrm{v}(\mathrm{x}, 0)=0, \mathrm{u}(\mathrm{x}, 1)=0, \mathrm{v}(\mathrm{x}, 1)=0 \\
\mathrm{u}(0, \mathrm{y})=0, \mathrm{v}(0, \mathrm{y})=1, \mathrm{u}(1, \mathrm{y})=0, \mathrm{v}(1, \mathrm{y})=1 \\
\theta(0, \mathrm{y})=1, \theta(1, \mathrm{y})=0,\left.\frac{\partial \theta}{\partial \mathrm{y}}\right|_{\mathrm{y}=0}=0,\left.\frac{\partial \theta}{\partial y}\right|_{\mathrm{y}=1}=0
\end{gathered}
$$


The boundary condition given by Eqs. (9) and (10) may also be expressed in terms of the stream function.

$$
\begin{gathered}
\psi(\mathrm{x}, 0)=0, \psi(\mathrm{x}, 1)=0, \psi(0, \mathrm{y})=0, \psi(1, \mathrm{y})=0 \\
\left.\frac{\partial \psi}{\partial \mathrm{y}}\right|_{\mathrm{y}=0}=0,\left.\frac{\partial \psi}{\partial \mathrm{y}}\right|_{\mathrm{y}=1}=0,\left.\frac{\partial \psi}{\partial \mathrm{x}}\right|_{\mathrm{x}=0}=1,\left.\frac{\partial \psi}{\partial \mathrm{x}}\right|_{\mathrm{x}=1}=1 .
\end{gathered}
$$

\section{NUMERICAL TECHNIQUE}

The dimensionless governing equations were solved for stream function, vorticity and temperature using the differential quadrature method originally proposed by Bellman et al. [18]. The basis of the method is to assume that the unknown functions can be locally approximated as polynomials. The first and second order partial derivatives of a two-variable function $\mathrm{F}(\mathrm{x}, \mathrm{y})$ at a point $\left(\mathrm{x}_{\mathrm{i}}, \mathrm{y}_{\mathrm{j}}\right)$ can be approximated as

$$
\begin{array}{ll}
F_{x}\left(x_{i}, y_{j}\right)=\sum_{k=1}^{N} a_{i k} F\left(x_{k}, y_{j}\right), & F_{y}\left(x_{i}, y_{j}\right)=\sum_{k=1}^{N} \bar{a}_{j k} F\left(x_{i}, y_{k}\right) \\
F_{x x}\left(x_{i}, y_{j}\right)=\sum_{k=1}^{N} b_{i k} F\left(x_{k}, y_{j}\right), & F_{y y}\left(x_{i}, y_{j}\right)=\sum_{k=1}^{N} \bar{b}_{j k} F\left(x_{i}, y_{k}\right)
\end{array}
$$

Here (N-1) is the degree of the polynomial assumed and the weight functions are given by Shu [19].

The stream function, vorticity and temperature ratio were assumed to behave as polynomials of $4^{\text {th }}$ degree in both $\mathrm{x}$ and $\mathrm{y}$ directions and $\mathrm{N}=5$ was used. Numerical mesh size $\mathrm{h}=0.01$ was used in both directions to insure a good accuracy. The velocity components at each mesh point were determined by differentiating the stream function using the expressions for the first order derivatives given by Eqs. (14) at each stage of the iterations. Vorticity on the walls of the enclosure was determined according to:

$$
\left.\omega\right|_{\eta=0}=\left.\mp \frac{\partial^{2} \psi}{\partial \eta^{2}}\right|_{\eta=0}
$$

where $\eta$ is the normal coordinate measured away from the wall and the differentiation was carried out using the expressions for the second order derivatives given by Eqs. (15). Iterations were stopped when the absolute values of the difference between the successive solutions for stream function, vorticity and temperature ratio at each mesh point are less than $10^{-6}$.

\section{ENTROPY GENERATION}

Local entropy generation is given by [14-16]:

$$
\mathrm{S}_{\mathrm{gen}}^{\prime \prime \prime}=\frac{\mathrm{k}}{\mathrm{T}_{0}^{2}}(\nabla \mathrm{T})^{2}+\frac{\mu}{\mathrm{T}_{0}} \phi
$$

The volumetric entropy generation rate for a two-dimensional flow in Cartesian coordinates can be defined as [11]:

$$
S_{\text {gen }}^{\prime}=\frac{k}{T_{0}^{2}}\left[\left(\frac{\partial \theta}{\partial x}\right)^{2}+\left(\frac{\partial \theta}{\partial y}\right)^{2}\right]+\frac{\mu}{T_{0}}\left(u^{2}+v^{2}\right)+\frac{\sigma_{e} B_{0}^{2}}{T_{0}} u^{2}
$$

Dimensionless entropy generation is given as 
Journal of Thermal Engineering, Research Article, Vol. 5, No. 6, Special Issue 10, pp. 240-251,

$$
\mathrm{N}_{\mathrm{s}}=\left[\left(\frac{\partial \theta}{\partial \mathrm{x}}\right)^{2}+\left(\frac{\partial \theta}{\partial \mathrm{y}}\right)^{2}\right]+\frac{\mathrm{Ecx} \operatorname{Pr}}{\Omega}\left[\left(\frac{\partial \psi}{\partial \mathrm{x}}\right)^{2}+\left(\frac{\partial \psi}{\partial \mathrm{y}}\right)^{2}\right]+\left[\operatorname{Ha}^{2}\left(\frac{\partial \psi}{\partial \mathrm{y}}\right)^{2}\right]
$$

Bejan number $(\mathrm{Be})$, which is the ratio of heat transfer irreversibility to the total entropy generation $\left(\mathrm{N}_{\mathrm{s}}\right)$ (total irreversibility due to heat transfer and fluid friction), can be expressed as

$$
\mathrm{Be}=\frac{\frac{\mathrm{k}}{\mathrm{T}_{0}^{2}}\left[\left(\frac{\partial \theta}{\partial \mathrm{x}}\right)^{2}+\left(\frac{\partial \theta}{\partial \mathrm{y}}\right)^{2}\right]}{\mathrm{N}_{\mathrm{s}}}
$$

\section{VALIDATION OF THE CODEANDGRID DEPENDENCY STUDY}

The results of present study were compared with the Davis [20] and Shu et al. [21] results as given in Table 1. As can be shown from the table, the present code shows good agreement with the literature. A grid dependency study was also conducted and a grid of $101 \times 101$ was selected [7].

Table 1. Comparison of the results for $\operatorname{Re}=0, \operatorname{Ra}=10^{4}, \operatorname{Pr}=0.71, \mathrm{Ha}=0$ and $\phi=0^{\circ}$

\begin{tabular}{|c|c|c|}
\hline & $\left|\psi_{\max }\right|$ & $\begin{array}{c}\left|\psi^{*} \max \right| \\
\left(\mathbf{m}^{2} / \mathbf{s}\right)\end{array}$ \\
\hline $\begin{array}{c}\text { Present } \\
\text { study }\end{array}$ & 5.074 & $1.0710^{-4}$ \\
\hline Davis [20] & 5.071 & $1.0710^{-4}$ \\
\hline $\begin{array}{c}\text { Shu et } \\
\text { al.[21] }\end{array}$ & 5.084 & $1.0710^{-4}$ \\
\hline
\end{tabular}

\section{RESULTS AND DISCUSSION}

Flow fields, temperature distributions and heat transfer rates and results for entropy generations are examined for different Richardson numbers, inclination angle of the enclosure, Hartmann and Prandtl number. The results were presented as streamlines, isotherms, Nusselt numbers, contours of entropy generation due to heat transfer irreversibility, contours of entropy generation due to fluid friction irreversibility and Bejan number. The Grashof number was kept at a constant value of $10^{4}$ for whole study.

Local entropy generation due to fluid friction and heat transfer irreversibilities is calculated once the values of velocities and temperature values are available from the converged solution of governing equations of continuity, momentum and energy. Figure 2 (a) to (d) show contours for entropy generation due to fluid friction irreversibility (on the left) and heat transfer irreversibility (on the right) at $\mathrm{Ha}=0$ and $\phi=0^{\circ}$ to see the effects of Richardson number. Entropy contours due to fluid flow irreversibility (FFI) are very dense in the corners for Ri $=0.1$ and 1 as shown from Figure 2 (a) and (b) (on the left), respectively. Values of contours are not given on the figure to have a track of details but the magnitude of entropy generation due to FFI is considerably smaller than its counterpart corresponding to the heat transfer. The structure of contours does not change considerably for $\mathrm{Ri}<1$ (forced convection dominant flow) and $\mathrm{Ri}=1$ (mixed convection). It is shown that as the Richardson number increases, the local entropy generation is increasingly confined to the neighborhood of the active walls of the lid-driven enclosures. With an increase in Richardson number, entropy generation is seen almost on the whole domain. However, this domain is decreased with decreasing of Richardson number. The results also show that Hartmann number affects the flow field and temperature distribution and it retards the convection. It is also directly affects the entropy generation. To see this effect on local entropy generation Figure 3 is plotted for different Hartmann number and $\mathrm{Ri}=1$ and $\phi=0^{\circ}$. As shown from the figure, entropy generation becomes weak with increasing of Hartmann number due to weakness of the convection heat transfer. Entropy contours were formed almost at the middle of the enclosure and they distributed from top to bottom due to interaction of hot and cold fluid. 
Journal of Thermal Engineering, Research Article, Vol. 5, No. 6, Special Issue 10, pp. 240-251, December, 2019

Table 2. Variation of the average Nusselt number and Bejan number

\begin{tabular}{|c|c|c|c|c|c|c|}
\hline $\mathbf{P r}$ & $\mathbf{R i}$ & $\mathbf{H a}$ & $\boldsymbol{\varphi}$ & $\boldsymbol{\phi}$ & $\overline{\mathrm{Nu}}$ & $\mathbf{B e}$ \\
\hline 0.71 & 0.1 & 0 & - & $0^{\circ}$ & 4.069 & 0.780 \\
\hline & 1.0 & 0 & - & $0^{\circ}$ & 2.192 & 0.671 \\
\hline & 10 & 0 & - & $0^{\circ}$ & 1.990 & 0.581 \\
\hline & 100 & 0 & - & $0^{\circ}$ & 2.007 & 0.284 \\
\hline 0.71 & 1 & 10 & $0^{\circ}$ & $0^{\circ}$ & 1.882 & 0.635 \\
\hline & 1 & 50 & $0^{\circ}$ & $0^{\circ}$ & 1.104 & 0.403 \\
\hline & 1 & 100 & $0^{\circ}$ & $0^{\circ}$ & 1.033 & 0.325 \\
\hline 0.71 & 0.1 & 10 & $0^{\circ}$ & $30^{\circ}$ & 3.372 & 0.744 \\
\hline & 0.1 & 10 & $0^{\circ}$ & $60^{\circ}$ & 3.384 & 0.746 \\
\hline & 0.1 & 10 & $0^{\circ}$ & $90^{\circ}$ & 3.392 & 0.748 \\
\hline & 0.1 & 10 & $0^{\circ}$ & $120^{\circ}$ & 3.387 & 0.746 \\
\hline & 0.1 & 10 & $0^{\circ}$ & $180^{\circ}$ & 3.353 & 0.741 \\
\hline 0.1 & 0.1 & 50 & $0^{\circ}$ & $0^{\circ}$ & 1.024 & 0.390 \\
\hline & 1.0 & 50 & $0^{\circ}$ & $0^{\circ}$ & 1.008 & 0.382 \\
\hline & 10 & 50 & $0^{\circ}$ & $0^{\circ}$ & 1.002 & 0.380 \\
\hline & 100 & 50 & $0^{\circ}$ & $0^{\circ}$ & 1.001 & 0.369 \\
\hline 0.71 & 10 & 10 & $0^{\circ}$ & $30^{\circ}$ & 1.837 & 0.577 \\
\hline & 10 & 10 & $0^{\circ}$ & $60^{\circ}$ & 1.743 & 0.582 \\
\hline & 10 & 10 & $0^{\circ}$ & $90^{\circ}$ & 1.118 & 0.537 \\
\hline & 10 & 10 & $0^{\circ}$ & $120^{\circ}$ & 1.743 & 0.582 \\
\hline & 10 & 10 & $0^{\circ}$ & $180^{\circ}$ & 1.693 & 0.570 \\
\hline 1 & 0.1 & 50 & $0^{\circ}$ & $0^{\circ}$ & 1.880 & 0.521 \\
\hline & 1.0 & 50 & $0^{\circ}$ & $0^{\circ}$ & 1.187 & 0.420 \\
\hline & 10 & 50 & $0^{\circ}$ & $0^{\circ}$ & 1.055 & 0.392 \\
\hline & 100 & 50 & $0^{\circ}$ & $0^{\circ}$ & 1.039 & 0.378 \\
\hline
\end{tabular}

Effects of inclination angle on entropy generation were analyzed for the case of $\mathrm{Ri}=10, \operatorname{Pr}=0.71$ and $\mathrm{Ha}=$ 10 as shown in Figure 4. Calculations were performed to see the effect of inclination angle for $\mathrm{Ri}<1$. It was obtained that there is no discernible effect of inclination angle on both heat transfer and entropy generation. The results were not given here to save space in the study. But Table 2 includes the values of Mean Nusselt and Bejan numbers which summarizes the effects of all chosen parameters. As given in the table values are almost same for Ri $<1$. On the contrary, entropy generation is affected with changing of inclination angle for values of Ri > 1. Entropy generation occupies the domain for $\phi=90^{\circ}$. For other angles, entropy generation is confined to the corners of the active sides.

As indicated above that Bejan number $(\mathrm{Be})$ defines the ratio of heat transfer irreversibility to the total entropy generation $\left(\mathrm{N}_{\mathrm{s}}\right)$ (total irreversibility due to heat transfer and fluid friction). Table 2 gives Bejan number for all governing parameters. As given in the table that Bejan number decreases with increasing of Richardson number. It means that flow friction becomes more effective with increasing of buoyancy effects. Similarly, it decreases with increasing of Hartmann number due to decreasing of convection heat transfer and flow strength. It becomes almost same with changing of inclination angle for $\mathrm{Ri}<1$, inclination angle of enclosure affects the Bejan number. Effects of fluid flow irreversibility on entropy generation become strong for $\phi=90^{\circ}$. Fluid flow irreversibility is more effective for lower Prandtl number when other parameters become constant. 
Journal of Thermal Engineering, Research Article, Vol. 5, No. 6, Special Issue 10, pp. 240-251, December, 2019

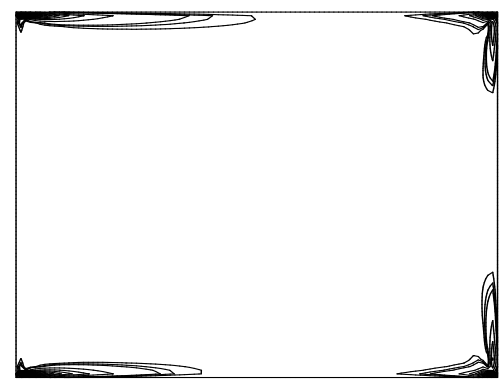

(a) $\mathrm{Ri}=0.1$

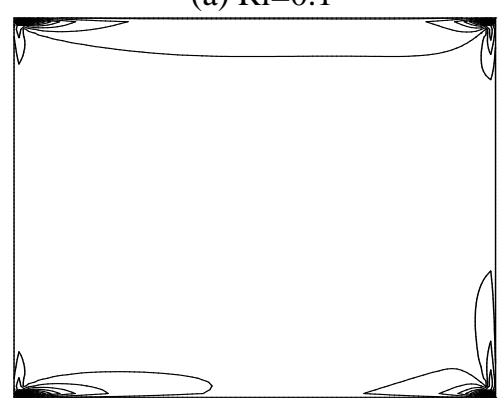

(b) $\mathrm{Ri}=1$

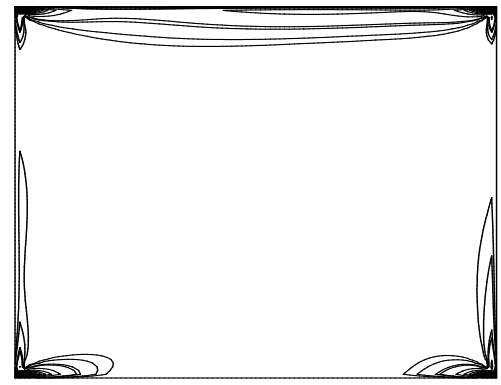

(c) $\mathrm{Ri}=10$

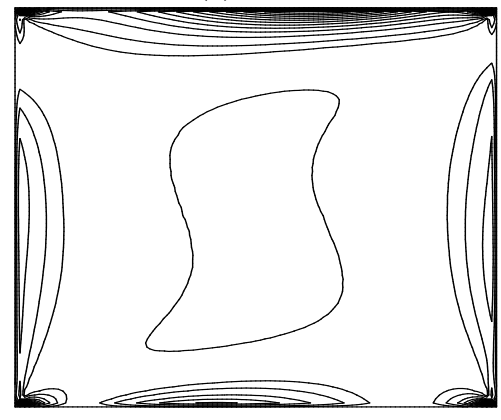

(d) $\mathrm{Ri}=100$
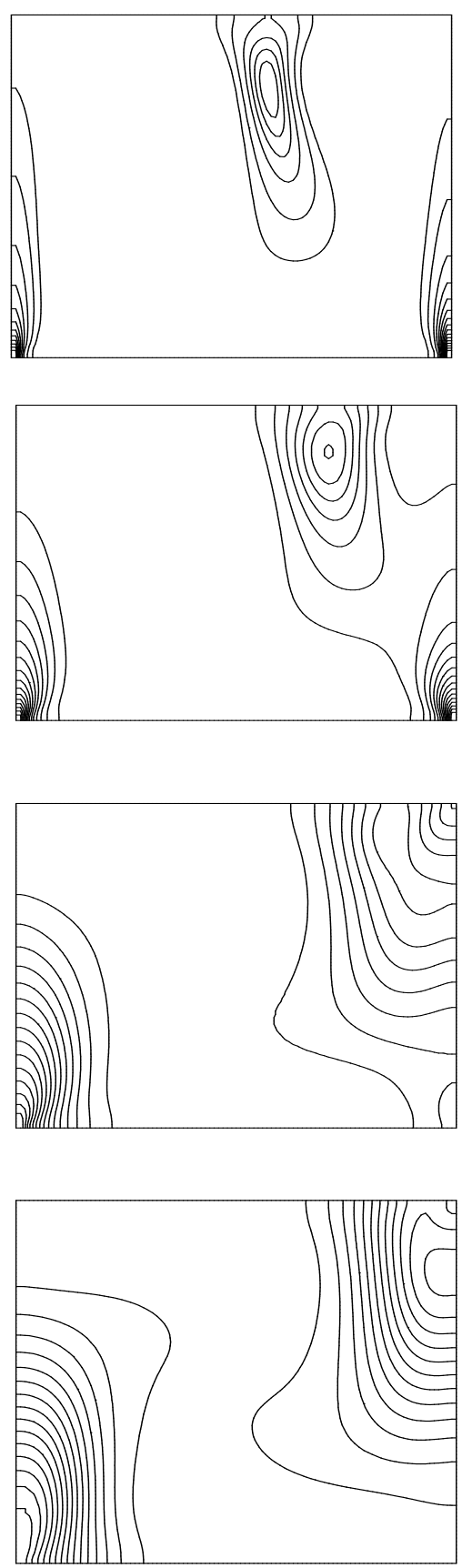

Figure 2. Entropy production due to fluid friction (on the left) and heat transfer (on the right) at $\mathrm{Ha}=0, \phi=0^{\circ}$, (a) Ri $=0.1$, (b) $\mathrm{Ri}=1$, (c) $\mathrm{Ri}=10$, (d) $\mathrm{Ri}=100$ 
Journal of Thermal Engineering, Research Article, Vol. 5, No. 6, Special Issue 10, pp. 240-251, December, 2019

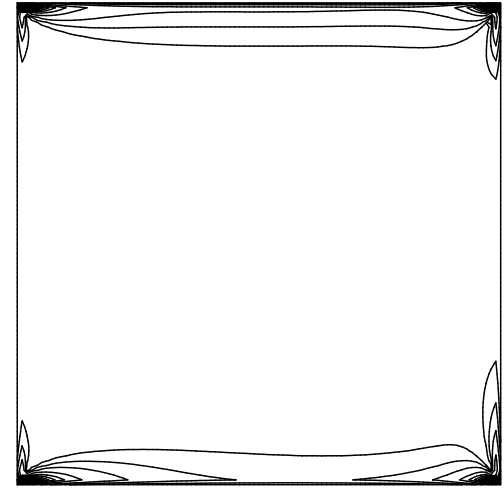

(a) $\mathrm{Ha}=10$

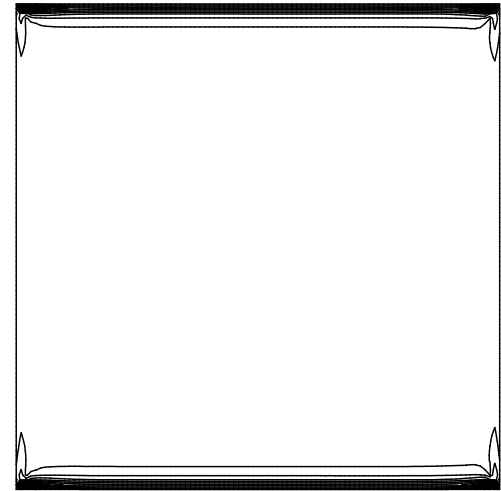

(b) $\mathrm{Ha}=50$

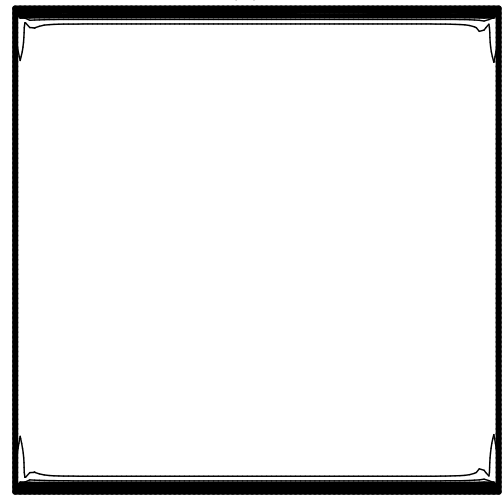

(c) $\mathrm{Ha}=100$
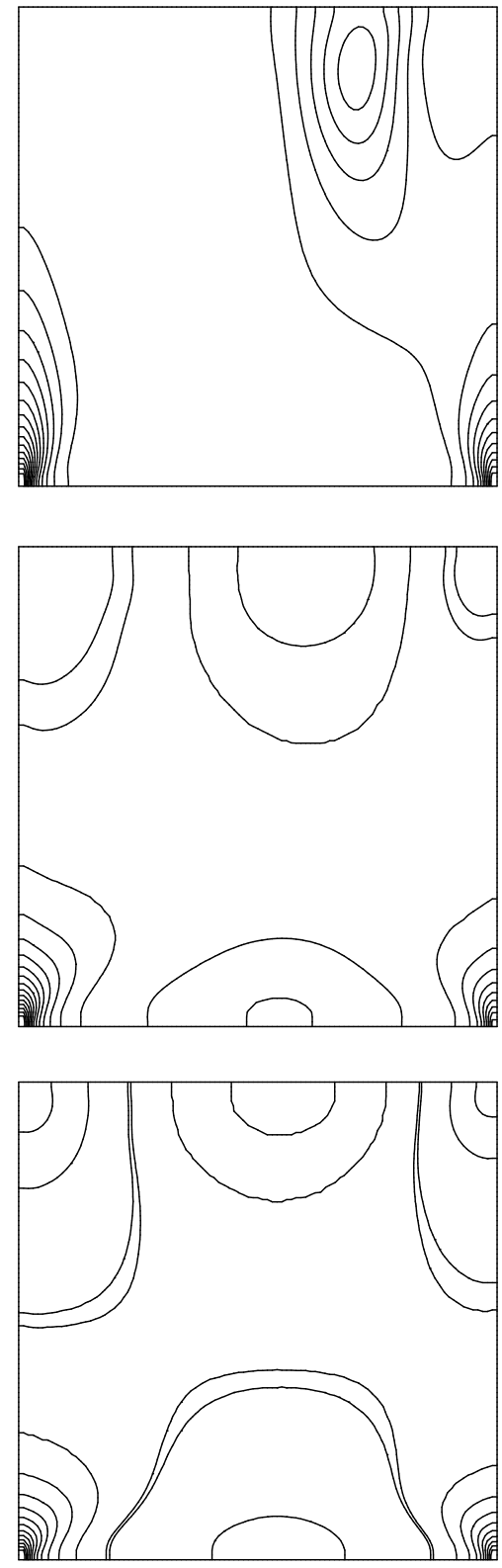

Figure 3. Entropy production due to heat transfer (on the left) and fluid friction (on the right) at $\mathrm{Ri}=1$ and $\phi=0^{\circ}$, (a) $\mathrm{Ha}=10$, (b) $\mathrm{Ha}=50$, (c) $\mathrm{Ha}=100$ 
Journal of Thermal Engineering, Research Article, Vol. 5, No. 6, Special Issue 10, pp. 240-251,

\section{December, 2019}

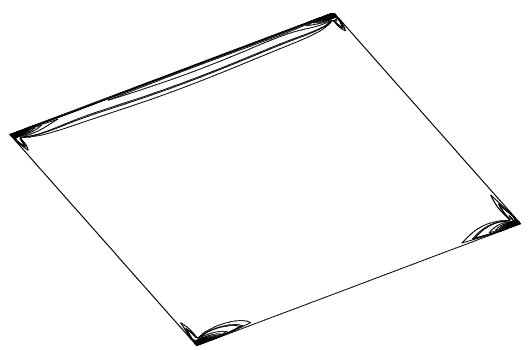

(a) $\phi=30^{\circ}$
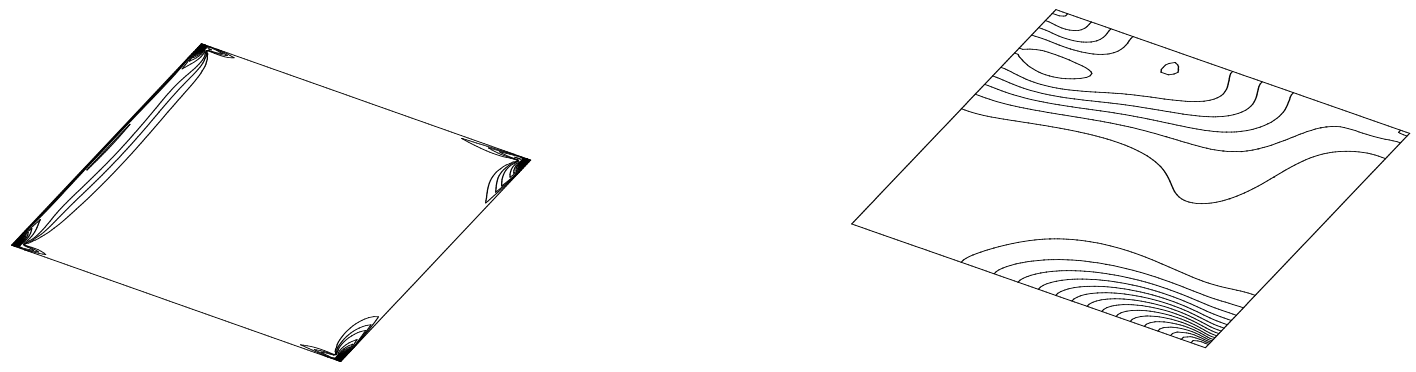

(b) $\phi=60^{\circ}$
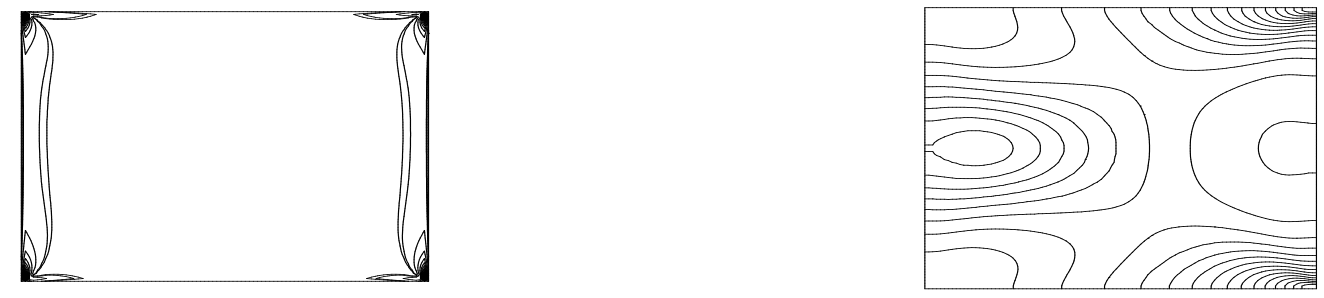

(c) $\phi=90^{\circ}$
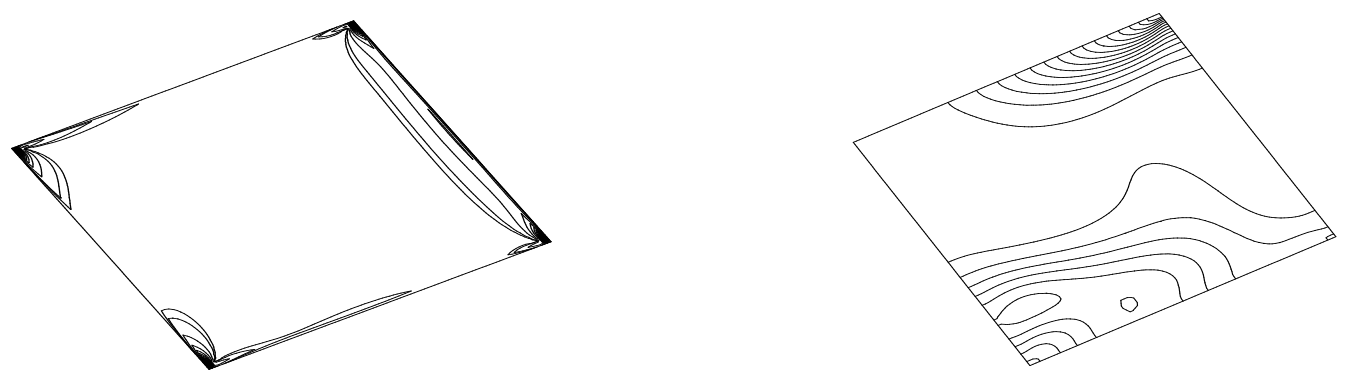

(d) $\phi=120^{\circ}$
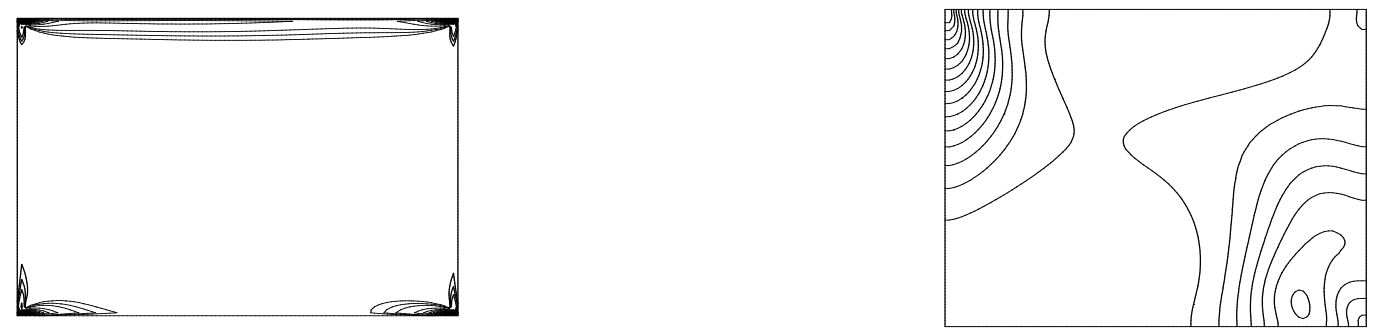

(e) $\phi=180^{\circ}$

Figure 4. Entropy production due to heat transfer (on the left) and fluid friction (on the right) at $\mathrm{Ri}=10, \operatorname{Pr}=0.71$ and $\mathrm{Ha}=10$, (a) $\phi=30^{\circ}$, (b) $\phi=60^{\circ}$, (c) $\phi=90^{\circ}$, (d) $\phi=120^{\circ}$, (e) $\phi=180^{\circ}$ 


\section{CONCLUSIONS}

Second law analysis of mixed convection in inclined double-sided lid-driven cavity under magnetic field has been studied. Two-dimensional equations of conservation of mass, momentum and energy have been solved using differential quadrature technique. The results showed that

- Strength of flow and convection heat transfer decreases with increasing of magnetic field.

- Fluid Flow irreversibility increases of increasing of Richardson and Hartmann number due to decreasing of convection heat transfer and strength of flow field.

- Fluid Flow irreversibility becomes more effective for lower Prandtl number when other parameters become constant.

- Inclination angle of enclosure becomes more effective parameter on entropy generation for Ri > 1 (natural convection). Thus, it can be a control parameter from the energy saving point of view in natural convection regime.

\section{NOMENCLATURE}

a Weight functions of the first order derivative

B Magnetic field strength

b Weight functions of the second order derivative

Be Bejan number

g Gravitational acceleration

Gr Grashof number

Ha Hartmann number

k Heat conduction coefficient

L Characteristic length

$\mathrm{Nu} \quad$ Nusselt number

$\mathrm{N}_{\mathrm{s}} \quad$ Total entropy generation number

$\mathrm{p}$ Pressure

Pr Prandtl number

q Heat flux

$\mathrm{Ra} \quad$ Rayleigh number

Re Reynolds number

Ri Richardson number

$\mathrm{S}^{\prime \prime \prime}$ gen $\quad$ entropy generation per unit volume

T Temperature

$\mathrm{T}_{0} \quad$ bulk temperature (K)

$\mathrm{U} \quad$ Speed of lid-driven wall

$\mathrm{u} \quad$ Velocity component in the $\mathrm{x}$ direction

$\mathrm{v} \quad$ Velocity component in the y direction

$\mathrm{x} \quad$ Cartesian coordinates

y Cartesian coordinates

$\alpha \quad$ Thermal diffusivity of the fluid

$\beta \quad$ Coefficient of thermal expansion of the fluid

$\eta \quad$ Dimensionless coordinate normal to the enclosure wall

$\theta \quad$ Dimensionless temperature

$\mu \quad$ Viscosity

$v \quad$ Kinematic viscosity

$\rho \quad$ Density of the fluid

$\sigma \quad$ Electrical conductivity of the fluid

$\phi \quad$ Angle of inclination of the enclosure, irreversibility. 
Journal of Thermal Engineering, Research Article, Vol. 5, No. 6, Special Issue 10, pp. 240-251, December, 2019

$\varphi \quad$ Angle of direction of the magnetic field with respect to the coordinate system

$\psi \quad$ Stream function

$\omega \quad$ Vorticity

\section{REFERENCES}

[1] Shankar, P. N., Deshpande, M. D. (2000). Fluid mechanics in the driven cavity. Annual review of fluid mechanics, 32(1), 93-136.

[2] Ghia, U. K. N. G., Ghia, K. N., Shin, C. T. (1982). High-Re solutions for incompressible flow using the NavierStokes equations and a multigrid method. Journal of computational physics, 48(3), 387-411.

[3] Sharif, M. A. R. (2007). Laminar mixed convection in shallow inclined driven cavities with hot moving lid on top and cooled from bottom. Applied thermal engineering, 27(5-6), 1036-1042.

[4] Torrance, K., Davis, R., Eike, K., Gill, P., Gutman, D., Hsui, A., Zien, H. (1972). Cavity flows driven by buoyancy and shear. Journal of Fluid Mechanics, 51(2), 221-231.

[5] Iwatsu, R., Hyun, J. M., Kuwahara, K. (1993). Mixed convection in a driven cavity with a stable vertical temperature gradient. International Journal of Heat and Mass Transfer, 36(6), 1601-1608.

[6] Mohamad, A., Viskanta, R. (1993). Flow and thermal structures in a lid-driven cavity heated from below. Fluid Dynamics Research, 12(3), 173.

[7] Ogut, E. B. (2017). Effects of Prandtl number and Magnetic field on Mixed Convection Heat Transfer in an Inclined Lid-driven Enclosure. Karaelmas Science and Engineering Journal, 7(1), 145-153.

[8] Ece, M. C., Büyük, E. (2006). Natural-convection flow under a magnetic field in an inclined rectangular enclosure heated and cooled on adjacent walls. Fluid Dynamics Research, 38(8), 564.

[9] Chamkha, A. J. (2002). Hydromagnetic combined convection flow in a vertical lid-driven cavity with internal heat generation or absorption. Numerical Heat Transfer: Part A: Applications, 41(5), 529-546.

[10] Chamkha, A. J. (1998). Mixed convection flow along a vertical permeable plate embedded in a porous medium in the presence of a transverse magnetic field. Numerical Heat Transfer, Part A Applications, 34(1), 93-103.

[11] Mahmud, S., Fraser, R. A. (2004). Magnetohydrodynamic free convection and entropy generation in a square porous cavity. International Journal of Heat and Mass Transfer, 47(14-16), 3245-3256.

[12] Yilbas, B. S., Shuja, S. Z., Gbadebo, S. A., Al-Hamayel, H. A., Boran, K. (1998). Natural convection and entropy generation in a square cavity. International journal of energy research, 22(14), 1275-1290.

[13] Magherbi, M., Abbassi, H., Brahim, A. B. (2003). Entropy generation at the onset of natural convection. International Journal of Heat and Mass Transfer, 46(18), 3441-3450.

[14] Narusawa, U. (2001). The second-law analysis of mixed convection in rectangular ducts. Heat and Mass Transfer, 37(2-3), 197-203.

[15] Mansour, R. B., Galanis, N., Nguyen, C. T. (2006). Dissipation and entropy generation in fully developed forced and mixed laminar convection. International journal of thermal sciences, 45(10), 998-1007.

[16] Tasnim, S. H., Mahmud, S. (2002). Mixed convection and entropy generation in a vertical annular space. Exergy, An International Journal, 2(4), 373-379.

[17] Mahmud, S., Fraser, R. A. (2002). Analysis of mixed convection-Radiation interaction in a vertical channel: Entropy generation. Exergy, an International journal, 2(4), 330-339.

[18] Bellman, R., Kashef, B. G., Casti, J. (1972). Differential quadrature: a technique for the rapid solution of nonlinear partial differential equations. Journal of computational physics, 10(1), 40-52.

[19] Shu, C. (2000). Mathematical Fundamentals of Differential Quadrature Method: Linear Vector Space Analysis and Function Approximation. In Differential Quadrature and Its Application in Engineering (pp. 1-24). Springer, London.

[20] De Vahl Davis, G. (1983). Natural convection of air in a square cavity: a bench mark numerical solution. International Journal for numerical methods in fluids, 3(3), 249-264. 
Journal of Thermal Engineering, Research Article, Vol. 5, No. 6, Special Issue 10, pp. 240-251,

December, 2019

[21] Shu, C., Ding, H., \& Yeo, K. S. (2003). Local radial basis function-based differential quadrature method and its application to solve two-dimensional incompressible Navier-Stokes equations. Computer methods in applied mechanics and engineering, 192(7-8), 941-954. 